\title{
Air pollution and hospital admissions for respiratory and cardiovascular diseases in Hong Kong
}

Tze Wai Wong, Tai Shing Lau, Tak Sun Yu, Anne Neller, Siu Lan Wong, Wilson Tam, Sik Wing Pang

\begin{abstract}
Objective-To investigate short term effects of concentrations of pollutants in ambient air on hospital admissions for cardiovascular and respiratory diseases in Hong Kong.

Methods-Retrospective ecological study. A Poisson regression was performed of concentrations of daily air pollutant on daily counts of emergency hospital admissions in 12 major hospitals. The effects of time trend, season, and other cyclical factors, temperature, and humidity were accounted for. Autocorrelation and overdispersion were corrected. Daily concentrations of nitrogen dioxide $\left(\mathrm{NO}_{2}\right)$, sulphur dioxide $\left(\mathrm{SO}_{2}\right)$, ozone $\left(\mathrm{O}_{3}\right)$, and particulate matter $<10 \mu \mathrm{m}$ in aerodynamic diameter $\left(\mathbf{P} \mathbf{M}_{10}\right)$ were obtained from seven air monitoring stations in Hong Kong in 1994 and 1995. Relative risks (RR) of respiratory and cardiovascular disease admissions (for an increase of $10 \mu \mathrm{g} / \mathrm{m}^{3}$ in concentration of air pollutant) were calculated.
\end{abstract}

Results-Significant associations were found between hospital admissions for all respiratory diseases, all cardiovascular diseases, chronic obstructive pulmonary diseases, and heart failure and the concentrations of all four pollutants. Admissions for asthma, pneumonia, and influenza were significantly associated with $\mathrm{NO}_{2}, \mathrm{O}_{3}$, and $\mathrm{PM}_{10}$. Relative risk (RR) for admissions for respiratory disease for the four pollutants ranged from 1.013 (for $\mathrm{SO}_{2}$ ) to $\mathbf{1 . 0 2 2}$ (for $\mathrm{O}_{3}$ ), and for admissions for cardiovascular disease, from 1.006 (for $\mathrm{PM}_{10}$ ) to 1.016 (for $\mathrm{SO}_{2}$ ). Those aged $\geqslant 65$ years were at higher risk. Significant positive interactions were detected between $\mathrm{NO}_{2}, \mathrm{O}_{3}$, and $\mathbf{P M}_{10}$, and between $\mathrm{O}_{3}$ and winter months.

Conclusions-Adverse health effects are evident at current ambient concentrations of air pollutants. Further reduction in air

Accepted 13 May 1999

Table 1 Mean summary statistics of daily pollutant concentrations $\left(\mu \mathrm{g} / \mathrm{m}^{3}\right)$, meteorological variables, and hospital admissions, 1994-5

\begin{tabular}{lccccc}
\hline & Min & 25th Percentile & Median & 75th Percentile & Max \\
\hline $\mathrm{NO}_{2}$ & 16.41 & 39.93 & 51.39 & 66.50 & 122.44 \\
$\mathrm{O}_{3}(8 \mathrm{~h})$ & 0 & 11.82 & 24.15 & 43.45 & 129.94 \\
$\mathrm{SO}_{2}$ & 2.74 & 12.45 & 17.05 & 25.01 & 68.49 \\
$\mathrm{PM}_{10}$ & 14.77 & 30.66 & 44.99 & 65.45 & 159.73 \\
${\mathrm{Temperature}\left({ }^{\circ} \mathrm{C}\right)}_{\text {Humidity }(\%)}$ & 9.34 & 18.40 & 24.00 & 27.15 & 30.96 \\
Respiratory admissions & 32.33 & 73.41 & 80.14 & 85.00 & 96.33 \\
Cardiovascular admissions & 54 & 116.75 & 131 & 150 & 232 \\
& 54 & 87 & 101 & 116 & 177 \\
\hline
\end{tabular}

pollution is necessary to protect the health of the community, especially that of the high risk group.

(Occup Environ Med 1999;56:679-683)

Keywords: air pollution; respiratory diseases; cardiovascular diseases

In recent years, time series studies have been used extensively in the study of air pollution and health outcomes. ${ }^{1-25}$ Positive associations between individual air pollutants and mortalities or morbidities have been found in many American and European studies. ${ }^{1-8}{ }^{10-30}$ Pooled estimates in 12 European cities of increase in daily mortality for an increase of $50 \mu \mathrm{g} / \mathrm{m}^{3}$ in concentrations of sulphur dioxide $\left(\mathrm{SO}_{2}\right)$ and particulates were $3 \%$ and $2 \%$ respectively. ${ }^{8}$ Few time series studies have been reported in Asian cities except Beijing. ${ }^{9}$ Hong Kong is a densely populated city in Southern China with hot, humid summers and mild, dry winters. Motor vehicles are the main source of air pollutants. In 1994 and 1995, the mean daily concentrations of nitrogen dioxide $\left(\mathrm{NO}_{2}\right)$ and particulates $<10 \mu \mathrm{m}$ in aerodynamic diameter $\left(\mathrm{PM}_{10}\right)$ were quite high, at $53.7 \mu \mathrm{g} / \mathrm{m}^{3}$ and $50.1 \mu \mathrm{g} / \mathrm{m}^{3}$ respectively. ${ }^{31}$ Compared with western European cities, Hong Kong had a low concentration of $\mathrm{SO}_{2}$ (daily mean $20.2 \mu \mathrm{g} / \mathrm{m}^{3}$ ), whereas ozone $\left(\mathrm{O}_{3}\right)$ concentrations were comparable (8 hour mean $\left.28.7 \mu \mathrm{g} / \mathrm{m}^{3}\right) .{ }^{11-13} 1931$ To elucidate the association between air pollutants and acute health effects, we performed a time series study on daily hospital admissions from 12 major hospitals and air pollutant concentrations from 7 air quality monitoring stations. The aim of the study was to examine the relation between concentrations of air pollutants and health effects from local data.

\section{Materials and methods}

HOSPITAL DATA

Emergency hospital admissions for respiratory and cardiovascular diseases in all 12 major hospitals for 1994 and 1995 were collected. A computerised format of patient data captured age, date of admission, and diagnosis on discharge from the ninth revision of the international classification of diseases (ICD-9). ${ }^{32}$ Two groups of diseases were chosen: diseases of the respiratory system (ICD 460-466, 471-478, 480-487, and 490-496) and diseases of the cardiovascular system (ICD 410-417, 420-438, and 440-444). Also, the following diseases were analysed separately: asthma (ICD 493), chronic obstructive pulmo- 

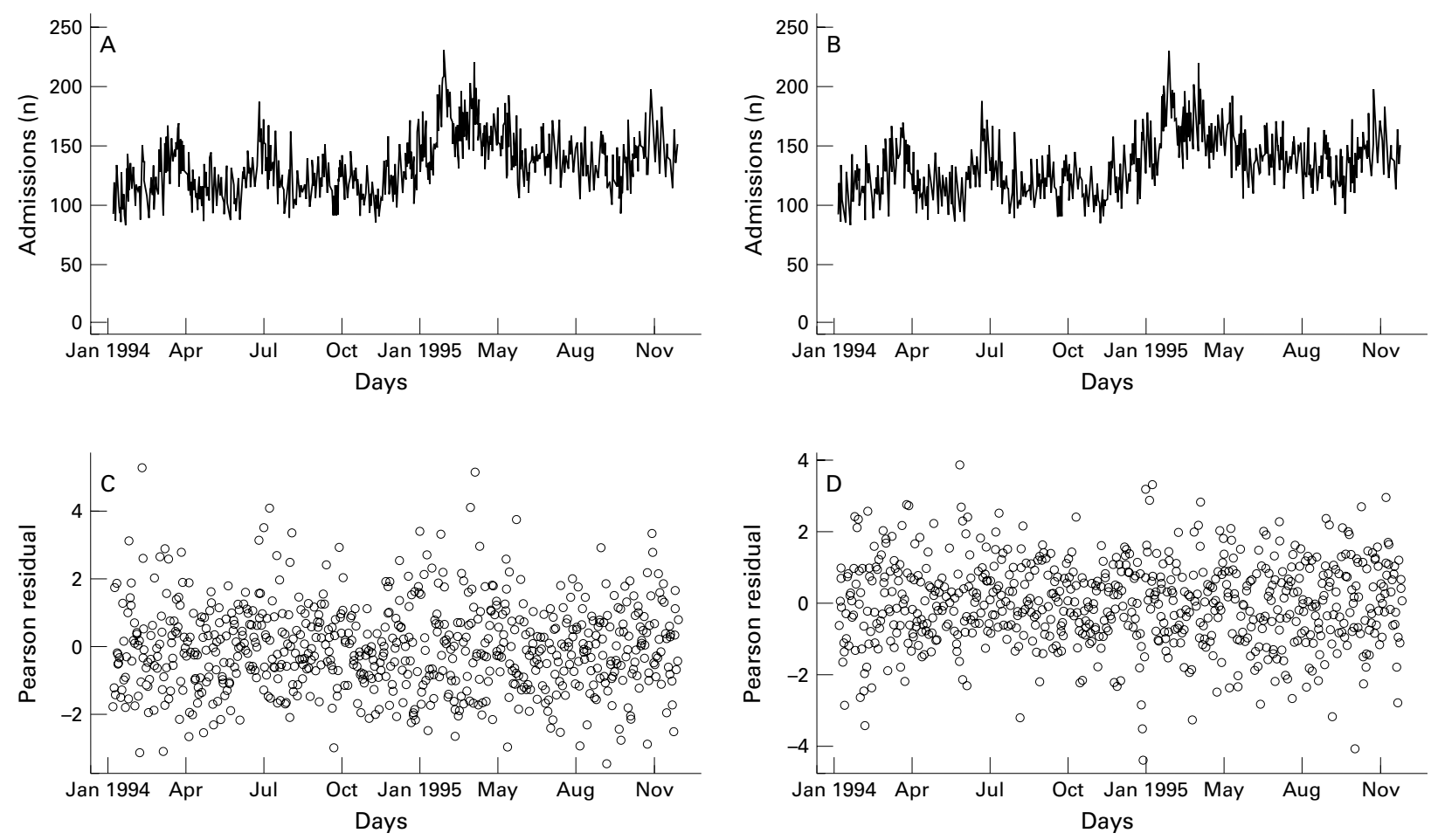

Figure 1 (A) Daily hospital admissions (respiratory diseases), 1994-5. (B) Daily hospital admissions (cardiovascular diseases), 1994-5. (C) Time plot of Pearson residuals of daily admissions for respiratory diseases based on the core model (without pollutants). (D) Time plot of Pearson residuals of daily admissions for cardiovascular diseases based on the core model (without pollutants).

nary disease (ICD 490-496), pneumonia and influenza (ICD 480-487), heart failure (ICD 428), ischaemic heart disease (ICD 410-414), and cerebrovascular disease (ICD 430-438).

DATA ON AIR QUALITY

Hourly concentrations of $\mathrm{SO}_{2}, \mathrm{NO}_{2}, \mathrm{PM}_{10}$, and $\mathrm{O}_{3}$ are monitored by a comprehensive network of stations with pulsed fluorescence, gas phase chemiluminescence, tapered element oscillating microbalance (TEOM), and ultraviolet absorption, respectively. ${ }^{31}$ Mean daily temperature and humidity were also measured. A rigourous quality control programme was implemented.

\section{STATISTICAL MODELLING}

We adopted the method described in the Air Pollution on Health: a European Approach (APHEA) protocol. ${ }^{43}$ This allowed flexibility in variations of local climate and levels of pollution. The daily number of hospital admissions was used as the dependent variable in a Poisson regression model. The following terms were included in the core model: linear and quadratic time trends; year; trigonometric terms to control for seasonality ( $\sin (2 \mathrm{k} \pi \mathrm{t} / 365)$ and $\cos (2 \mathrm{k} \pi \mathrm{t} / 365)$, where $\mathrm{k}=1,2,3,4$, and 6 represented cycles of $12,6,4,3$, and 2 months respectively); days of the week; holiday effect; mean temperature; and humidity. To control for autocorrelation, autoregressive terms up to an order of five were tested. After the core model was fitted, different lags of concentrations of air pollutants were added. The best lag was chosen based on the Akaike's information criterion value of the model. Brännäs and Johansson's method (which accounts for overdispersion by modifying the covariance ma- trix $\left.{ }^{\star}\right)$ was used in calculating the $95 \%$ confidence intervals (95\% CIs) of the relative risks (RRs). ${ }^{34}$

SINGLE POLLUTANT MODEL

Daily concentrations of each air pollutant were added separately into the core model to obtain the respective partial regression coefficients $(\beta)$ and RR. Delayed effects were investigated with single day lags and cumulative lags up to 5 days for $\mathrm{O}_{3}$ and 3 days for the other air pollutants. Relative risks were calculated for admissions with respiratory and cardiovascular diseases and for the specific diseases already mentioned.

INTERACTIONS BETWEEN POLLUTANTS

In some studies, a multipollutant approach was adopted, either by including all air pollutants into a model, or with stepwise procedures. ${ }^{3} 10$ In the APHEA protocol, concerns of collinearity between air pollutants preclude the inclusion of all pollutants into a multiple pollutant model. ${ }^{4}$ To explore interactions between pollutants, we performed pairwise analyses by entering two pollutants and their interaction term into the core model. Each pollutant was analysed as a continuous variable with the other pollutant as a dichotomous variable (high and low concentrations, with the median as the cut off point). Interaction of each pollutant with the cold season (December to March, months with a mean temperature below $20^{\circ} \mathrm{C}$ ) was similarly examined.

\footnotetext{
* A consistent estimator of the asymptotic covariance matrix is: $\operatorname{Cov}(\beta)=\mathrm{A}^{-1} \mathrm{~B} \mathrm{~A}^{-1}$, where $\mathrm{B}=\mathrm{X}^{\prime} \mathrm{V} \mathrm{X}$, with $\mathrm{V}$ an estimator of Cov (y), y being the vector of time series observations on the count variable, and $A=$ covariance matrix of the ML estimator of $\beta$.
} 
Table 2 Relative risks (95\% CIs) $/ 10 \mu \mathrm{g} / \mathrm{m}^{3}+$ increase in air pollutant for respiratory and cardiovascular admissions by age group (single pollutant model)

\begin{tabular}{|c|c|c|c|c|}
\hline $\begin{array}{l}\text { Pollutant: } \\
\text { age group }\end{array}$ & Respiratory ad & issions & Cardiovascula & admissions \\
\hline $\mathrm{NO}_{2}$ & Lag $0-3$ days & & Lag 0-1 day & \\
\hline $0-4$ & $1.020^{\star \star \star}$ & (1.010 to 1.030$)$ & - & \\
\hline $5-64$ & $1.023^{\star \star \star}$ & (1.011 to 1.034$)$ & 1.008 & (0.998 to 1.018$)$ \\
\hline$\geqslant 65$ & $1.024^{\star \star \star}$ & (1.014 to 1.035$)$ & $1.016^{\star \star \star}$ & (1.009 to 1.023$)$ \\
\hline Overall & $1.020^{\star \star \star}$ & (1.013 to 1.028$)$ & $1.013^{\star \star \star}$ & (1.007 to 1.020$)$ \\
\hline $\mathrm{SO}_{2}$ & Lag 0 day & & Lag 0-1 day & \\
\hline $0-4$ & 1.005 & (0.991 to 1.018$)$ & - & \\
\hline $5-64$ & 1.008 & (0.996 to 1.021$)$ & 1.004 & (0.989 to 1.020$)$ \\
\hline$\geqslant 65$ & $1.023^{\star \star \star}$ & (1.012 to 1.036$)$ & $1.021^{\star \star \star}$ & (1.010 to 1.032$)$ \\
\hline Overall & $1.013^{\star \star}$ & (1.004 to 1.021 ) & $1.016^{\star \star}$ & $(1.0061 .026)$ \\
\hline $\mathrm{PM}_{10}$ & Lag $0-3$ days & & Lag $0-2$ days & \\
\hline $0-4$ & $1.019^{\star \star \star}$ & (1.011 to 1.028$)$ & — & \\
\hline $5-64$ & $1.017^{\star \star \star}$ & (1.009 to 1.026$)$ & 1.005 & (0.997 to 1.013$)$ \\
\hline$\geqslant 65$ & $1.018^{\star \star}$ & (1.010 to 1.026$)$ & $1.008^{\star \star}$ & (1.002 to 1.013$)$ \\
\hline Overall & $1.016^{\star \star \star}$ & (1.010 to 1.022$)$ & $1.006^{\star \star}$ & (1.002 to 1.011$)$ \\
\hline $\mathrm{O}_{3}$ & Lag $0-3$ days & & Lag 0-5 days & \\
\hline $0-4$ & $1.019^{\star \star \star}$ & (1.009 to 1.030$)$ & - & \\
\hline $5-64$ & $1.022^{\star \star \star}$ & (1.011 to 1.034$)$ & $1.012^{\star}$ & (1.000 to 1.025$)$ \\
\hline$\geqslant 65$ & $1.029^{\star \star \star}$ & (1.018 to 1.039$)$ & $1.013^{\star \star}$ & (1.004 to 1.022$)$ \\
\hline Overall & $1.022^{\star \star \star}$ & (1.015 to 1.029$)$ & $1.013^{\star \star}$ & (1.005 to 1.021$)$ \\
\hline
\end{tabular}

${ }^{\star} \mathrm{p}<0.05 ;{ }^{\star \star} \mathrm{p}<0.01 ;{ }^{\star \star \star} \mathrm{p}<0.001$

†1 ppm of $\mathrm{NO}_{2}=1880 \mu \mathrm{g} / \mathrm{m}^{3} ; 1 \mathrm{ppm}$ of $\mathrm{SO}_{2}=2860 \mu \mathrm{g} / \mathrm{m}^{3} ; 1 \mathrm{ppm}$ of $\mathrm{O}_{3}=1960 \mu \mathrm{g} / \mathrm{m}^{3}$.

\section{Results}

Table 1 shows the pollutant concentrations, weather variables, and hospital admissions during the study period. Pollutant concentrations between different monitoring stations were strongly correlated (Pearson's correlation coefficient $r$, ranged from 0.88 to 0.99 for $\mathrm{O}_{3}$ and $\mathrm{PM}_{10}, 0.68$ to 0.89 for $\mathrm{NO}_{2}$ and 0.41 to 0.80 for $\left.\mathrm{SO}_{2}\right) \cdot \mathrm{PM}_{10}$ was strongly correlated with $\mathrm{NO}_{2}(r=0.79)$. For the other pollutants, $r$ ranged from -0.12 to 0.51 . Those aged $\geqslant 65$ accounted for $68 \%$ and $38 \%$ of admissions for cardiovascular and respiratory diseases respectively. Children under 5 accounted for $31 \%$ of respiratory diseases but only $0.5 \%$ of cardiovascular diseases. The mean numbers of admissions were slightly higher on days with a mean temperature below $20^{\circ} \mathrm{C}$ and lower on days above $25^{\circ} \mathrm{C}$ compared with the $20-25^{\circ} \mathrm{C}$ range. Time series plots of the daily numbers of hospital admissions for respiratory and cardiovascular diseases and their residuals are shown in the figure. No seasonal or other long term pattern was apparent in the residuals.

We found significant associations between admissions for respiratory and cardiovascular diseases and an increase of $10 \mu \mathrm{g} / \mathrm{m}^{3}$ for all four pollutants (table 2). A lag effect (cumulative from day 0 to $\geqslant 1$ days) was found for all pollutants except $\mathrm{SO}_{2}$ for respiratory admissions. The overdispersion parameter $(\phi)$ was 1.63 for respiratory diseases and 1.40 for cardiovascular diseases, and the respective autocorrelation coefficients $(r)$ were -0.003 and 0.028 . Relative risks among those aged $\geqslant 65$ were higher than in other age groups for all pollutants except $\mathrm{PM}_{10}$. Table 3 shows RRs for individual diseases. Significant RRs of chronic obstructive pulmonary disease (COPD) and heart failure were found for all four pollutants. Significant RRs for asthma, pneumonia, and influenza were found for all pollutants except $\mathrm{SO}_{2}$. Ischaemic heart disease and cerebrovascular diseases were not significantly associated with any of the pollutants. Interactions between pollutants and climate are shown in table 4 . For respiratory admissions, significant positive interactions were found for $\mathrm{O}_{3}$ with high $\mathrm{PM}_{10}$ concentrations. For cardiovascular admissions, significant interactions were found for both $\mathrm{PM}_{10}$ and $\mathrm{NO}_{2}$ with high $\mathrm{O}_{3}$ concentration, and for $\mathrm{O}_{3}$ with high $\mathrm{PM}_{10}$ concentrations. Ozone had a significant positive interaction with cold season for both respiratory and cardiovascular admissions.

\section{Discussion}

This study represents one of few time series studies on health effects of air pollution reported in Asia. The study period was short but the mean daily admissions for respiratory and cardiovascular illnesses were quite large. Confounding by severely cold weather (which has been associated with increased mortalities and morbidities), a concern in some studies, ${ }^{2320}$ does not pose a problem here because of the mild winters.

Our findings were broadly consistent with those in European countries and the United States. ${ }^{1-3}$ 5-8 10-20 2324 The effect size for $\mathrm{PM}_{10}$, a $1.6 \%$ increase in respiratory admissions for an increase of $10 \mu \mathrm{g} / \mathrm{m}^{3}$, falls within the range $(0.8 \%-3.4 \%)$ reported by Dockery and Pope. ${ }^{27}$ It should be noted that $\mathrm{PM}_{10}$ was measured by tapered element oscillating microbalance (TEOM) which may underestimate the true concentration of particulates. The association between $\mathrm{O}_{3}$ and respiratory admissions was in

Table 3 Relative risks (95\% CIs) of hospital admissions for individual diseases per $10 \mu \mathrm{g} / \mathrm{m}^{3}$ increase in the concentrations of air pollutants

\begin{tabular}{|c|c|c|c|c|}
\hline & $\mathrm{NO}_{2}$ & $\mathrm{SO}_{2}$ & $P M_{10}$ & $\mathrm{O}_{3}$ \\
\hline \multirow[t]{3}{*}{ Asthma } & Lag $0-3$ days & Lag 0 day & Lag $0-3$ days & Lag $0-2$ days \\
\hline & $1.026^{\star \star}$ & 1.017 & $1.015^{\star}$ & $1.031^{\star \star \star}$ \\
\hline & (1.010 to 1.042$)$ & (0.998 to 1.036$)$ & (1.002 to 1.028$)$ & (1.017 to 1.046$)$ \\
\hline \multirow[t]{3}{*}{ Chronic obstructive pulmonary diseases } & Lag $0-3$ day & Lag 0 day & Lag $0-3$ days & Lag $0-5$ days \\
\hline & $1.029^{\star \star \star}$ & $1.023^{\star \star \star}$ & $1.019^{\star \star \star}$ & $1.032^{\star \star \star}$ \\
\hline & (1.019 to 1.040$)$ & (1.011 to 1.035$)$ & (1.011 to 1.027$)$ & (1.021 to 1.042$)$ \\
\hline \multirow[t]{3}{*}{ Pneumonia and influenza } & Lag $0-3$ days & Lag 4 days & Lag $0-3$ days & Lag $0-3$ days \\
\hline & $1.028^{\star \star \star}$ & 0.990 & $1.025^{\star \star \star}$ & $1.022^{\star \star \star}$ \\
\hline & (1.015 to 1.041$)$ & (0.977 to 1.004$)$ & (1.014 to 1.036$)$ & (1.009 to 1.035$)$ \\
\hline \multirow[t]{3}{*}{ Heart failure } & Lag $0-3$ days & Lag 0 day & Lag $0-3$ days & Lag $0-5$ days \\
\hline & $1.044^{\star \star \star}$ & $1.036^{\star \star}$ & $1.048^{\star \star \star}$ & $1.038^{\star \star \star}$ \\
\hline & (1.025 to 1.063$)$ & (1.013 to 1.059$)$ & (1.032 to 1.064$)$ & (1.018 to 1.059$)$ \\
\hline \multirow{3}{*}{ Ischaemic heart disease } & Lag $0-1$ day & Lag 1 day & Lag $0-1$ day & Lag 5 days \\
\hline & 1.010 & 1.010 & 1.007 & 1.005 \\
\hline & (0.999 to 1.020$)$ & (0.995 to 1.025$)$ & (0.999 to 1.015$)$ & (0.997 to 1.013$)$ \\
\hline \multirow[t]{3}{*}{ Cerebrovascular diseases } & Lag $0-1$ day & Lag 3 days & Lag 2 days & Lag 0 day \\
\hline & 1.008 & 0.990 & 1.003 & 0.992 \\
\hline & (0.998 to 1.018$)$ & (0.978 to 1.002$)$ & (0.995 to 1.010$)$ & (0.983 to 1.001$)$ \\
\hline
\end{tabular}

${ }^{\star} \mathrm{p}<0.05 ;{ }^{\star \star} \mathrm{p}<0.01 ;{ }^{\star \star \star} \mathrm{p}<0.001$ 
Table 4 Relative risks (95\% CI) of pollutants at high level $\dagger$ of another pollutant and cold season $\neq$

\begin{tabular}{|c|c|c|c|c|}
\hline Pollutant & $\mathrm{High} \mathrm{NO}_{2}$ & High $P M_{10}$ & $\mathrm{High} \mathrm{O}_{3}$ & Cold season \\
\hline \multicolumn{5}{|c|}{ Respiratory admissions: } \\
\hline $\mathrm{NO}_{2}$ & - & $1.009(0.993-1.025)$ & $1.013(0.999-1.026)$ & $1.004(0.988-1.020)$ \\
\hline $\mathrm{PM}_{10}$ & $0.984(0.968-1.001)$ & - & $1.005(0.995-1.016)$ & $1.006(0.994-1.017)$ \\
\hline $\mathrm{O}_{3}$ & $1.005(0.992-1.019)$ & $1.016^{\star}(1.004-1.029)$ & - & $1.018^{\star \star}(1.005-1.032)$ \\
\hline \multicolumn{5}{|c|}{ Cardiovascular admissions: } \\
\hline $\mathrm{NO}_{2}$ & - & $1.002(0.988-1.016)$ & $1.013^{\star}(1.002-1.024)$ & $1.103(0.999-1.027)$ \\
\hline $\mathrm{PM}_{10}^{2}$ & $1.007(0.995-1.020)$ & - & $1.017^{\star \star \star}(1.007-1.028)$ & $1.000(0.989-1.011)$ \\
\hline $\mathrm{O}_{3}$ & $1.012(0.998-1.026)$ & $1.021^{\star}(1.005-1.038)$ & - & $1.023^{\star \star}(1.007-1.039)$ \\
\hline
\end{tabular}

†High level: level above the median; RR were expressed using low level as reference.

$\ddagger$ December to March

$\star 0.05>p>0.01$

$\star \star 0.01>\mathrm{p}>0.001$

$\star \star \star \mathrm{p}<0.001$

agreement with findings elsewhere. ${ }^{512}$ A significant association between $\mathrm{NO}_{2}$ and respiratory admissions, not found in other studies, ${ }^{24} 28$ might be due to correlations with $\mathrm{PM}_{10}$. Adverse respiratory effects of $\mathrm{SO}_{2}$ were detectable even at relatively low concentrations. Significant associations with cardiovascular morbidities have not been as widely reported elsewhere as respiratory illnesses. ${ }^{25}{ }^{27}$

Compared with respiratory and cardiovascular admissions, the RR for certain disease codings such as asthma, COPD, and heart failure were higher and seemed to be more sensitive indicators of health effect, whereas other diseases (ischaemic heart disease and cardiovascular disease) showed no association. A positive association was found between concentrations of carbon monoxide (CO) and heart failure in United States cities. ${ }^{21}$ However, $\mathrm{CO}$ concentrations were unavailable in this study. The absence of significant association between the pollutants and ischaemic heart disease or cardiovascular disease contrasts with findings by Pönkä et $a l^{22}$ and Wordley, who reported a significant association between admissions for cardiovascular disease and $\mathrm{PM}_{10}$ (at lower concentrations than ours) on the same day. ${ }^{23}$

Elderly people had higher RRs for respiratory and cardiovascular admissions for all four pollutants than other age groups except children aged $0-4$ years for respiratory admissions and $\mathrm{PM}_{10}$. The identification of target diseases and high risk groups would be useful in finding suitable air quality guidelines in environmental health.

Although the best lag of each pollutant was chosen by statistical criteria, the chemical and toxicological properties of the pollutants might offer plausible explanations. Sulphur dioxide is very soluble in the upper respiratory tract and exerts an immediate irritant effect on the respiratory mucosa. This might explain the absence of lag effect for respiratory admissions. A cumulative lag was found for the less soluble $\mathrm{O}_{3}$ and $\mathrm{NO}_{2}$. Both are highly reactive oxidants which can cause inflammation of the pulmonary epithelium. Low concentrations of $\mathrm{O}_{3}$ cause pulmonary function decrement, biochemical changes, and respiratory symptoms. ${ }^{35}$ $\mathrm{NO}_{2}$ forms nitrous and nitric acid in the respiratory epithelium and alters host defence in animal studies. ${ }^{35}$ Both gases at high concentrations have caused delayed pulmonary oedema. The pathophysiology of the chemically hetero- geneous particulates is less clear. Acid aerosols have been incriminated as a possible cause of ill health. ${ }^{29}{ }^{30}$ In Hong Kong, the main constituents of $\mathrm{PM}_{10}$ are carbon and sulphates. ${ }^{31}$ The acidity of particulates has not been assessed here. The reason for the different lag periods between respiratory and cardiovascular diseases remains unclear.

Collinearity between pollutants was a common problem in time series studies, especially when a multipollutant model is attempted. To study interactions between pollutants, we performed the more conservative pairwise analysis. Significant interactions were found between $\mathrm{PM}_{10}, \mathrm{NO}_{2}$, and $\mathrm{O}_{3}$. The $\mathrm{NO}_{2}$ and $\mathrm{O}_{3}$ are strong oxidants, which may explain their synergistic effect. Mechanisms for the interaction between particulates and the oxidants are complex. Gilmour et al hypothesised that the pathogenicity of $\mathrm{PM}_{10}$ particles involved the generation of hydroxyl radicals which led to oxidative stress at the cellular level. ${ }^{36} \mathrm{~A}$ multiple pollutant analysis on mortality in Philadelphia, however, found no interaction between particulates and the gaseous pollutants. ${ }^{3}$ Synergistic effects between $\mathrm{SO}_{2}$ and particulates have been reported in Athens ${ }^{17}$ but were not found here, possibly because of low $\mathrm{SO}_{2}$ concentrations. In Spokane, where $\mathrm{SO}_{2}$ concentrations were even lower, Schwartz reported similar findings of a significant health effect of particulates independent of $\mathrm{SO}_{2} \cdot{ }^{20}$ Climatic effects on risk estimates were more obvious in some studies other than ours, illustrating the importance of local pollution mix and meteorological characteristics. ${ }^{20}$ The underlying reason for a significant positive interaction between $\mathrm{O}_{3}$ and the cold season (December to March) was unclear.

As with all ecological studies, this study is limited by the lack of precise exposure estimates, and caution should be exercised in inferring cause-effect relations. As more and more epidemiological studies in different parts of the world provide independent and consistent observations of adverse health outcomes at current concentrations of pollutants in ambient air, the need to re-examine national environmental health policies and standards is evident. Collinearity issues and limitations of the time series design preclude the identification of the underlying pollutant causing the health effects, be it ultrafine particles or acid aerosols. Interactions among pollutants and their patho- 
physiological mechanisms remain to be clarified. Despite our incomplete understanding, stricter control of air pollutants at source (whether by transport policies or regulatory changes) should lower the concentrations of the main ambient pollutants and thus reduce mortalities and morbidities. This study was partly funded by the Hong Kong Environmental
Protection Department. We thank Dr Fung Hong at the Hospital Authority for providing the hospital data and Miss Andromeda Wong for proof reading the manuscript.

1 Kelsall JE, Samet JM, Zeger SL, et al. Air pollution and mortality in Philadelphia, 1974-88. Am f Epidemio 1997;146:750-62.

2 Samet JM, Zeger SL, Berhane K. Particulate air pollution and daily mortality. Replication and validation of selected studies. The Phase I report of the particle epidemiology evaluation project. Cambridge, MA: Health Effects Institute, 1995:3-

3 Samet JM, Zeger SL, et al. Particulate air pollution and daily mortality: analysis of the effects of weather and multiple air pollutants. The Phase I.B Report of the particle epidemiology evaluation project. Cambridge, MA: Health Effects Institute, 1997:14-21.

4 Katsouyanni K, Schwartz J, Spix C, et al. Short term effects of air pollution on health: a European approach using epidemiologic time series data: the APHEA protocol. 7 Epidemiol Community Health 1996:50:S12 18 .

5 Ponce de Leon A, Anderson HR, Bland JM, et al. Effects of air pollution on daily hospital admissions for respiratory disease in London between 1987-88 and 1991-92. F Epidemiol Community Health 1996;50:S63-70.

6 Saldiva PHN, Dockery DW, Pope CA, et al. Air pollution and mortality in elderly people: a time-series study in Sao and mortality in elderly people: a time-series study

7 Borja-Aburto VH, Loomis DP, Bangdiwala SL, et al. Ozone, suspended particulates, and daily mortality in Mexico City. Am F Epidemiol 1997;145:258-68.

8 Katsouyanni K, Touloumi G, Spix C, et al. Short term effects of ambient sulphur dioxide and particulate matter on mortality in 12 European cities: results from time serie data from the APHEA project. BMf 1997;314:1658-63.

$9 \mathrm{Xu} \mathrm{X}$, Dockery DW, Gao J, et al. Air pollution and daily mortality in residential areas of Beijing, China. Arch Environ Health 1994;49:216-22.

10 Walters S, Griffiths RK, Ayres JG. Temporal association between hospital admissions for asthma in Birmingham and ambient levels of sulphur dioxide and smoke. Thorax 1994;49:133-40.

11 Schouten JP, Vonk JM, de Graaf A. Short term effects of air pollution on emergency hospital admissions for respiratory disease: results of the APHEA project in two major cities in The Netherlands, 1977-89. J Epidemiol Community Health 1996;50:S22-9.

12 Pönkä A, Virtanen M. Asthma and ambient air pollution in Helsinki. F Epidemiol Community Health 1996;50:S59-62.

13 Dab W, Medina S, Quenel P, et al. Short term respiratory health effects of ambient air pollution: results of the APHEA project in Paris. $f$ Epidemiol Community Health 1996;50:S42-6.

14 Zmirou D, Barumandzadeh T, Balducci F, et al. Short term effects of air pollution on mortality in the city of Lyon, France, 1985-90. F Epidemiol Community Health 1996;50: S $30-5$
15 Vigotti MA, Rossi G, Bisanti L, et al. Short term effects of urban air pollution on respiratory health in Milan, Italy, 1980-9. F Epidemiol Community Health 1996;50:S71-5.

16 Sunyer J, Castellsague J, Saez M, et al. Air pollution and mortality in Barcelona. $\mathcal{F}$ Epidemiol Community Health 1996;50:S76-80.

17 Touloumi G, Samoli E, Katsouyanni K. Daily mortality and "winter type" air pollution in Athens, Greece: a time series analysis within the APHEA project. $\mathcal{F}$ Epidemiol Community Health 1996;50:S47-51.

18 Bacharova L, Fandakova K, Bratinka J, et al. The association between air pollution and the daily number of deaths: findings from the Slovak Republic contribution to the APHEA project. F Epidemiol Community Health 1996;50:S19-21.

19 Zmirou D, Schwartz J, Saez M, et al. Time-series analysis of air pollution and cause-specific mortality. Epidemiology 1998;9:495-503.

20 Schwartz J. Air pollution and hospital admissions for respiratory disease. Epidemiology 1996;7:20-8.

21 Morris RD, Naumova EN, Munasinghe RL. Ambient air pollution and hospitalization for congestive heart failure among elderly people in seven large US cities. Am f Public Health 1995;85:1361-5.

22 Pönkä A, Virtanen M. Low-level air pollution and hospital admissions for cardiac and cerebrovascular diseases in Helsinki. Am Э Public Health 1996;86:1273-80.

23 Wordley J, Walters S, Ayres JG. Short term variations in hospital admissions and mortality and particulate air pollution. Occup Environ Med 1997;54:108-16.

24 Spix C, Wichmann HE. Daily mortality and air pollutants: indings from Köln, Germany. 7 Epidemiol Community Health 1996;50:S52-8.

25 Brunekreef B, Dockery DW, Krzyzanowski M. Epidemiologic studies on short-term effects of low levels of major ambient air pollution components. Environ Health Perspect 1995;103:3-13.

26 Dockery DW, Pope CA III, Xu X, et al. An association between air pollution and mortality in six US cities. N Engl f Med 1993;329:1753-9.

27 Dockery DW, Pope CA III. Acute respiratory effects of particulate air pollution. Annu Rev Public Health 1994;15:10732.

28 Samet JM, Lambert WE, Skipper BJ, et al. Nitrogen dioxide and respiratory illness in children. Cambridge MA: Health Effects Institute, 1993. (Research Report No 58.)

29 Raizenne ME, Burnett RT, Stern B, et al. Acute lung function responses to ambient acid aerosol exposures in children. Environ Health Perspect 1989;79:179.

30 Utell MJ, Morrow PE, Speers DM, et al. Airway responses to sulfate and sulfuric acid aerosols in asthmatics. Am Rev Respir Dis 1983;128:444.

31 Environmental Protection Department. Air quality in Hong Kong 1996. Hong Kong: Hong Kong Government, 1997:4-13.

32 World Health Organization. International classification of diseases, 1975 revision. Geneva: World Health Organisation, 1977.

33 Schwartz J, Spix C, Touloumi G, et al. Methodological issues in studies of air pollution and daily counts of deaths or hospital admissions. $\mathcal{f}$ Epidemiol Community Health 1996;50:S3-11.

34 Brännäs K, Johansson P. Time series count data regression. Commun Statist Theory Meth 1994;23:2907-25.

35 Gardner DE, Gardner SCM. Toxicology of air pollution. In: Cockerham LG, Lorris G, Shane BS, eds. Basic environmental toxicology. Boca Raton: CRC Press, 1994:287-319.

36 Gilmour PS, Brown DM, Lindsay TG, et al. Adverse health effects of $\mathrm{PM}_{10}$ particles: involvement of iron in generation of hydroxyl radical. Occup Environ Med 1996;53:817-22. 